\title{
Practical Issues to Prevent Stroke Associated with Non-valvular Atrial Fibrillation
}

\author{
Chi Kyung Kim, Seunguk Jung, Byung-Woo Yoon \\ Department of Neurology, and Clinical Research Center for Stroke, Biomedical Research Institute, Seoul National University Hospital, Seoul, Korea
}

Stroke associated with non-valvular atrial fibrillation (NVAF) is one of the most important subtypes of ischemic stroke, and its importance is becoming even more apparent in an aging population. To assess the risk of stroke associated with $\mathrm{NVAF}_{1}$ the $\mathrm{CHADS}_{2}$ and $\mathrm{CHA}_{2} \mathrm{DS}_{2}$ VASc scores are mainly used. Such scores can be used to predict the recurrence and prognosis of ischemic stroke. In addition, new oral anticoagulants (NOACs) and devices are being evaluated in the prevention of stroke associated with NVAF in addition to treatment with the conventional oral anticoagulant, warfarin. Since clinical experience with NOACs is not globally sufficient, a cautious approach is needed.

Keywords Cardioembolic stroke; Atrial fibrillation; $\mathrm{CHADS}_{2}$; New oral anticoagulants; Prevention; Review
Correspondence: Byung-Woo Yoon Department of Neurology, Seoul National University Hospital, 101 Daehak-ro, Jongno-gu, Seoul 110-744, Korea Tel: $+82-2-2072-2875$

Fax: +82-2-3672-7553

E-mail: bwyoon@snu.ac.kr

Received: August 18, 2013

Revised: September 10, 2013

Accepted: September 11, 2013

This work was supported by a grant from the Korea Healthcare Technology R\&D Project, Ministry of Health and Welfare Republic of Korea (HI10C2020).

The authors have no financial conflicts of interest.

\section{Introduction}

Cardioembolic stroke, which is an important subtype of ischemic stroke, involves a large infarct volume and multiple vascular territories. The neurologic deficits are grave and develop abruptly. ${ }^{1,2}$ Because cardioembolic stroke is generally severe and frequently recurs, its long-term mortality is high..$^{3,4}$ In addition, hemorrhagic transformation occurs frequently because of early or delayed recanalization. ${ }^{5,6}$ Cardioembolic stroke accounts for $14-30 \%$ of all ischemic stroke. ${ }^{7-12}$ In Korea, it accounts for approximately $17 \%$, and the proportion is increasing (Figure 1). ${ }^{13,14}$ Cardioembolic stroke is associated with chronological age ${ }^{7}$ and is thought to be one of the most important subtypes of ischemic stroke in aged or aging populations.

Non-valvular atrial fibrillation (NVAF) is the most important cause of cardioembolic stroke, and patients with NVAF can com- plain of palpitations, chest pain, breathing difficulty, dizziness, or fainting. ${ }^{15}$ However, many patients do not have any symptoms or complain of vague and non-specific symptoms. ${ }^{16,17}$ Probability of stroke incidence in patients with atrial fibrillation is $3-4 \%,{ }^{18}$ and the risk of stroke increased by five times in all age groups. ${ }^{19,20}$ The percentage of strokes attributable to atrial fibrillation increases steeply from $1.5 \%$ at age 50 to 59 years to $23.5 \%$ at age 80 to 89 years. ${ }^{21}$ The prevalence of atrial fibrillation is globally increasing over time. In the United States, the number of patients with atrial fibrillation was 2.1 million in 1997, but it increased to 2.3 million in 2001. It is estimated to increase to 5.6 million in 2050.22 The increased prevalence of atrial fibrillation is caused by improved survival rates of patients with heart disease. ${ }^{23}$ The prevalence of atrial fibrillation significantly increases with an increase in age. ${ }^{24}$ In Korea, $57 \%$ of individuals with atrial fibrillation are older than 65 years, and the prevalence of atrial 


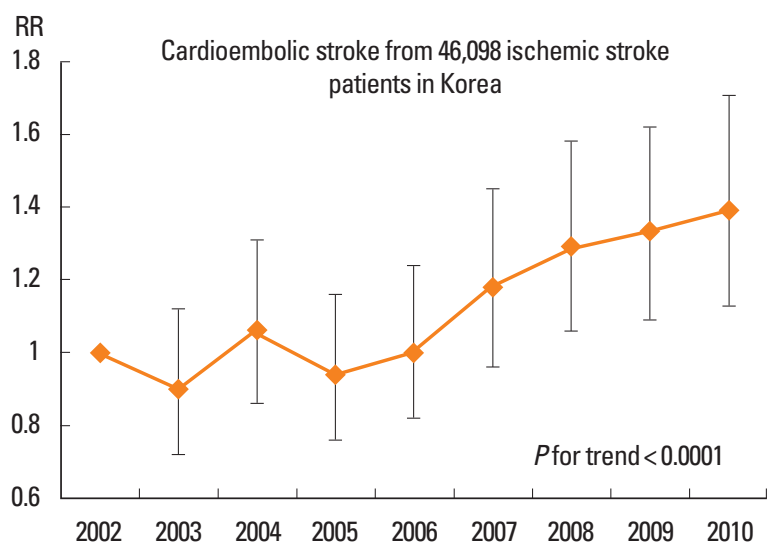

Figure 1. Trend of cardioembolic stroke in Korea. ${ }^{13}$

fibrillation is the highest in those older than 80 years. ${ }^{25}$ The importance of atrial fibrillation in ischemic stroke will further increase in Korean society, which is rapidly aging.

\section{Risk assessment of stroke in patients with NVAF}

Risk factors increasing the incidence of stroke in patients with NVAF are known to be female gender, old age, history of stroke or transient ischemic attack (TIA), hypertension, heart failure, diabetes, and vascular diseases. ${ }^{23,26,27}$ History of stroke or TIA increases the risk of stroke in patients with NVAF by three times. ${ }^{26}$ The incidence of stroke in patients with NVAF in their 70s is seven times that of patients in their $40 \mathrm{~s}^{28}$ When patients with NVAF have hypertension, the risk of stroke is thrice as high. ${ }^{19}$ Since a risk stratification scale for embolic events in patients with NVAF was developed based on integration of these risk factors, it can be used to assess the risk of stroke in patients with NVAF and to select adequate preventive drugs.

To classify the risk of stroke in patients with NVAF, several models are currently utilized. The representative stratification systems currently being used include the $\mathrm{CHADS}_{2}$ and $\mathrm{CHA}_{2} \mathrm{DS}_{2-}$ VASc scores (Table 1). ${ }^{29,30}$ The $\mathrm{CHADS}_{2}$ score is widely used as the risk stratification scale, but after considering additional risk factors such as vascular disease, gender, and age of 65-74 years, a more specific evaluation can be made. The scale reflecting these risk factors is the $\mathrm{CHA}_{2} \mathrm{DS}_{2}$-VASc score. If a patient is classified into the group of low risk ( 0 or 1 ) in the point system by using the $\mathrm{CHADS}_{2}$ score, the $\mathrm{CHA}_{2} \mathrm{DS}_{2}$-VASc score can be helpful for a more comprehensive risk assessment. ${ }^{30}$ In addition, the HAS-BLED score, which is a convenient bleeding risk scale, is prepared from risk factors and a systematic review of bleeding in patients with NVAF (Table 2).$^{31}$ If the HAS-BLED score is $\geq 3$, a patient is classified into the high-risk group for
Table 1. $\mathrm{CHADS}_{2}$ and $\mathrm{CHA}_{2} \mathrm{DS}_{2}$-VASc scores

\begin{tabular}{lclc}
\hline & Letter & \multicolumn{1}{c}{ Conditions } & Points \\
\hline CHADS $_{2}$ & $\mathrm{C}$ & Congestive heart failure & 1 \\
& $\mathrm{H}$ & Hypertension* & 1 \\
& $\mathrm{~A}$ & Age $\geq 75$ years & 1 \\
& $\mathrm{D}$ & Diabetes mellitus & 1 \\
& $\mathrm{~S}_{2}$ & Prior stroke or TIA or systemic thromboembolism & 2 \\
& Total & & 6 \\
$\mathrm{CHA}_{2} \mathrm{DS}_{2}$-VASc & $\mathrm{C}$ & Congestive heart failure & 1 \\
& $\mathrm{H}$ & Hypertension & 1 \\
& $\mathrm{~A}_{2}$ & Age $\geq 75$ years & 2 \\
& $\mathrm{D}$ & Diabetes mellitus & 1 \\
& $\mathrm{~S}_{2}$ & Prior stroke or TIA or systemic thromboembolism & 2 \\
& V & Vascular diseases & 1 \\
& $\mathrm{~A}$ & Age 65-74 years & 1 \\
& $\mathrm{Sc}$ & Sex category (female) & 1 \\
& Total & 9 \\
\hline
\end{tabular}

*Hypertension is defined as blood pressure consistently $>140 / 90 \mathrm{mmHg}$ (or treated hypertension on medication).

Table 2. HAS-BLED score

\begin{tabular}{llc}
\hline Letter & \multicolumn{1}{c}{ Conditions } & Points \\
\hline $\mathrm{H}$ & Hypertension & 1 \\
$\mathrm{~A}$ & Abnormal renal or liver function & 1 or 2 \\
$\mathrm{~S}$ & Stroke & 1 \\
$\mathrm{~B}$ & Bleeding & 1 \\
$\mathrm{~L}$ & Labile INRs & 1 \\
$\mathrm{E}$ & Elderly (age $\geq 65$ years) & 1 \\
$\mathrm{D}$ & Drugs or alcohol & 1 or 2 \\
\hline
\end{tabular}

bleeding. ${ }^{32}$ When antithrombotic therapy is started, special care and regular observation are required in this group. In addition, microbleeds predict intracranial bleeding associated with warfarin. ${ }^{33,34}$

For the past 60 years, when the need for anticoagulation therapy was determined based on the calculated risk of stroke in patients with NVAF, warfarin has been administered. Previous studies demonstrated that warfarin was superior to other antiplatelet drugs in preventing stroke in patients with NVAF $^{35,36}$ In addition, it has been reported that the stroke is less severe when it occurs in patients taking warfarin. ${ }^{37-39}$ Some patients have a very high tendency of relapse stroke, and stroke may recur despite the use of warfarin after stroke associated with NVAF. Although the primary reason is that warfarin is not properly administered or the international normalized ratio (INR) does not enter the target, other risk factors for recurrence of stroke are old age, female gender, and a history of stroke. ${ }^{40}$ If large artery atherosclerosis such as carotid or vertebral atherosclerosis is associated with NVAF, the recurrence rate of stroke also increases. ${ }^{41}$ In addition, a meta-analysis reported that stroke may be more recurrent in Asian individuals taking warfarin compared to other races. ${ }^{42}$ In this context, the $\mathrm{CHADS}_{2}$ score can 
be useful in predicting the recurrence of stroke in patients with stroke associated with NVAF. ${ }^{40,42}$ Furthermore, it was recently reported that the $\mathrm{CHADS}_{2}$ score can be used to predict the prognosis of stroke associated with NVAF (Figure 2). ${ }^{43,44}$

\section{Emergence of new anticoagulants}

Warfarin, a vitamin K antagonist, was the only oral anticoagulant available for a long time. However, its narrow therapeutic window and numerous food and drug interactions affect its safety, efficacy, and patient compliance. In addition, its slow onset of action and variable pharmacologic effects make it difficult to maintain the appropriate antithrombotic effect. ${ }^{45} \mathrm{~A}$ metaanalysis reported that $44 \%$ of bleeding complications with warfarin were associated with supratherapeutic INRs, and $48 \%$ of thromboembolic events occurred in the subtherapeutic range. ${ }^{46}$ These drawbacks have encouraged the development of new anticoagulants. Several new oral anticoagulants (NOACs) have been developed in the past 10 years. ${ }^{47}$ Three of them were approved for use in the prevention of stroke and systemic embolism in patients with NVAF: dabigatran, a direct thrombin inhibitor, and rivaroxaban and apixaban, activated factor $\mathrm{X}$ inhibi-

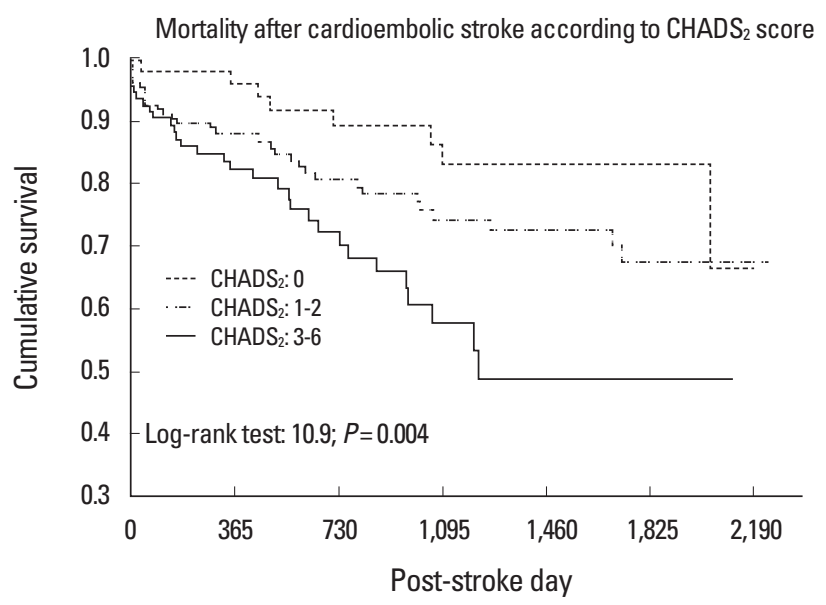

Figure 2. $\mathrm{CHADS}_{2}$ score as a prognostic factor after cardioembolic stroke. ${ }^{43}$ tors. ${ }^{48-50}$ They have predictable anticoagulant effects and fewer food and drug interactions, which allow a fixed dosing regimen without the need for monitoring. However, strict patient compliance is required to maintain the desired anticoagulation levels. When rapid reversal of the anticoagulant effect is needed in the event of a major bleeding or emergency surgery, there are no specific antidotes and standardized tests to monitor the anticoagulant status, which is a weakness of NOACs. ${ }^{51}$

In terms of efficacy, according to the three randomized clinical trials that compared the efficacy of three NOACs and warfarin, NOACs were not always superior to warfarin. The rates of the primary efficacy outcomes of any type of stroke or systemic embolism were significantly lower in the dabigatran $150 \mathrm{mg}$ and apixaban groups compared to the warfarin group. Those in the dabigatran $110 \mathrm{mg}$ and rivaroxaban groups were not significantly lower than those in the warfarin group. In addition, all three studies had poor or moderately controlled patients (defined as INR in the target range $<65 \%$ of the time) as a control group. ${ }^{48-50}$ Follow-up studies in which the control groups were divided based on INR level did not show the superiority of the dabigatran $150 \mathrm{mg}$ dose compared with the well-controlled group (INR in the target range $\geq 65 \%$ of the time). ${ }^{52}$ The superiority of the primary efficacy outcome in apixaban use was mostly caused by a reduction in hemorrhagic stroke, and there was no statistically significant difference in ischemic stroke rate. ${ }^{49}$ Therefore, if the patient is well-controlled with warfarin and has minimal complications, the use of NOACs may be controversial (Table 3).

In terms of safety, the major bleeding complication rate in the dabigatran $110 \mathrm{mg}$ and apixaban groups was significantly lower than that in the warfarin group. However, there was no significant difference between the dabigatran $150 \mathrm{mg}$ and rivaroxaban groups and the warfarin group (Table 3). ${ }^{48-50}$ Considering subtypes of bleeding, the intracerebral hemorrhage (ICH) rate was significantly lower with both doses of dabigatran, but the major gastrointestinal (GI) bleeding rate was significantly higher in the dabigatran $150 \mathrm{mg}$ and rivaroxaban groups. ${ }^{50,53} \mathrm{The} \mathrm{ICH}$

Table 3. Summary of 3 clinical trials related to new oral anticoagulants

\begin{tabular}{|c|c|c|c|c|c|c|c|c|}
\hline Trial & Intervention & $\begin{array}{l}\text { Duration of } \mathrm{f} / \mathrm{u} \\
\text { (year, median) }\end{array}$ & $\begin{array}{c}\text { Primary outcome* } \\
(\% / y)\end{array}$ & $\begin{array}{l}\text { Rate ratio } \\
\text { (95\% Cls) }\end{array}$ & $P$ value & $\begin{array}{c}\text { Major bleeding } \\
(\% / y)\end{array}$ & $\begin{array}{l}\text { Rate ratio } \\
\text { (95\% Cls) }\end{array}$ & $P$ value \\
\hline \multirow[t]{3}{*}{ RE-LY48 } & Warfarin & 2.0 & 1.71 & & & 3.57 & & \\
\hline & Dabigatran $110 \mathrm{mg}$ bid & & 1.54 & $0.90(0.74-1.10)^{\dagger}$ & 0.30 & 2.87 & $0.80(0.70-0.93)^{\dagger}$ & $<0.01$ \\
\hline & Dabigatran 150 mg bid & & 1.11 & $0.65(0.52-0.81)^{\dagger}$ & $<0.01$ & 3.32 & $0.93(0.81-1.07)^{\dagger}$ & 0.32 \\
\hline \multirow[t]{2}{*}{ ROCKET-AF ${ }^{50}$} & Warfarin & 1.9 & 2.40 & & & 3.40 & & \\
\hline & Rivaroxaban $15-20 \mathrm{mg}$ qd & & 2.10 & $0.88(0.75-1.03)^{\ddagger}$ & 0.12 & 3.60 & $1.04(0.90-1.20)^{\ddagger}$ & 0.58 \\
\hline \multirow[t]{2}{*}{ ARISTOTLE ${ }^{49}$} & Warfarin & 1.8 & 1.60 & & & 3.09 & & \\
\hline & Apixaban 2.5-5 mg bid & & 1.27 & $0.79(0.66-0.95)^{\ddagger}$ & 0.01 & 2.13 & $0.69(0.60-0.80)^{\ddagger}$ & 0.00 \\
\hline
\end{tabular}

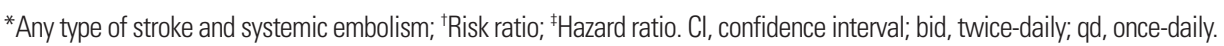


rate was significantly lower and the GI bleeding rate was not significantly different in the apixaban group. ${ }^{49}$ Hemorrhagic stroke rates related to receiving warfarin were higher in Asian patients than in non-Asian patients, but hemorrhagic stroke rates were significantly reduced by dabigatran in both Asian and non-Asian patients compared with individuals receiving warfarin. ${ }^{54}$ In non-hemorrhagic adverse events, approximately $10 \%$ of the patients in the dabigatran group complained of severe dyspepsia and approximately $21 \%$ of them discontinued the drugs. These symptoms were likely caused by the tartaric acid core composed of dabigatran etexilate. Tartaric acid created an acidic environment and increased the absorption of the drug independent of gastric $\mathrm{pH} .{ }^{55}$ Approximately $0.8 \%$ of patients taking dabigatran in the RE-LY trial experienced myocardial infarction. It was not statistically significant compared with the group taking warfarin, but it showed greater tendencies. ${ }^{56} \mathrm{~A}$ meta-analysis of 7 studies including the RE-LY trial showed that the risk of myocardial infarction and cardiac death or unstable angina was significantly increased in the dabigatran group compared with the warfarin group. ${ }^{57}$

The bioavailability of dabigatran is only $6.5 \%$ and is not influenced by the coadministration of food. Approximately $80 \%$ of the drug is excreted unchanged in the urine, while only $20 \%$ is excreted in the feces. Therefore, it is contraindicated in severe renal impairment. It is not metabolized by cytochrome $\mathrm{P} 450$ isoenzymes. Thus, it is substantially unaffected by mild to moderate hepatic failure. ${ }^{58}$ Because of the low plasma protein binding, it may be dialyzable when rapid reversal of its anticoagulation effects is needed. ${ }^{59}$ The bioavailability of rivaroxaban is dosedependent and influenced by the coadministration of food. The bioavailability at $10 \mathrm{mg}$ and $20 \mathrm{mg}$ in the fasting state is $80 \%$ $100 \%$ and $66 \%$, respectively. Taken with meals, its absorption is delayed but increased. Thus, therapeutic doses of rivaroxaban should be taken with meals. ${ }^{60}$ Approximately $66 \%$ is excreted in the urine, and only $28 \%$ is excreted in the feces. The safety and efficacy of rivaroxaban were consistent with warfarin in patients with moderate renal impairment, and it was also observed in Japanese patients. ${ }^{61}$ Two-thirds of the drug is converted into inactive metabolites through different CYP450 isoenzymes (CYP3A4/5 or CYP2J2) and CYP-independent mechanisms. ${ }^{62}$ In this context, rivaroxaban should be avoided in patients with severe renal failure or moderate to severe hepatic impairment. The bioavailability of apixaban is approximately $50 \%$ and is not influenced by the coadministration of food. ${ }^{63}$ One-third of the drug is metabolized through the cytochrome P-450 isoenzyme system (mainly CYP3A4/5). Approximately 25\% is excreted in the urine, and $>50 \%$ is excreted in the feces.$^{64}$ It may be suitable for patients with mild to moderate renal impairment because of its low renal excretion.

\section{Special circumstances for NOACs}

As previously mentioned, patients stabilized on warfarin may prefer to continue the same. However, the convenience and efficacy of NOACs in the patients with inadequate INR are cause to consider the transition to NOACs. Transition to warfarin also may be needed in patients who are unable to continue on NOACs. In this situation, safe transition between anticoagulants is an important issue in current practice. In previous trials including patients who had warfarin before starting on dabigatran, the highest INR permitted at the time of transition was 2.0 or $2.3{ }^{65,66}$ whereas in the Rivaroxaban Once-Daily, Oral, Direct Factor X Inhibition Compared With Vitamin K Antagonism for Prevention of Stroke and Embolism Trial in Atrial Fibrillation (ROCKET AF), it was 3.0..$^{50}$ In these trials, the overlap was not associated with an increased risk for bleeding. In transition from NOACs to warfarin, it is necessary to take into account the expected onset of warfarin as well as the half-life of the NOACs. The mean time to achieve therapeutic range (INR 2-3) was approximately 5 days. The half-life of NOACs highly depends on

Table 4. Suggested strategy for conversion to and from new oral anticoagulants

\begin{tabular}{lcc}
\hline NOAC of choice & Approach and timing of conversion \\
\hline From VKAs to NOACs & Discontinue VKA and start dabigatran when the INR is $<2$ \\
Dabigatran & Start rivaroxaban or apixaban when the INR falls to $<3$ or $<2$, respectively \\
Rivaroxaban or apixaban & $\mathrm{CrCl}\left(\mathrm{mL} / \mathrm{min} / 1.73 \mathrm{~m}^{2}\right)$ & Start VKA 3 days before stopping dabigatran \\
From NOACs to VKAs & $\geq 50$ & Start VKA 2 days before stopping dabigatran \\
Dabigatran & $30-50$ & Start VKA 1 day before stopping dabigatran \\
& $15-30$ & Start VKA 4 days before stopping rivaroxaban \\
Rivaroxaban & $\geq 50$ & Start VKA 3 days before stopping rivaroxaban \\
& $30-50$ & Start VKA 2 days before stopping rivaroxaban \\
Apixaban & $15-30$ & Insufficient data \\
\hline
\end{tabular}

VKA, vitamin K antagonist; NOAC, new oral anticoagulant; INR, international normalized ratio; $\mathrm{CrCl}$, creatinine clearance. 
Table 5. Perioperative management of the new oral anticoagulants

\begin{tabular}{lll}
\hline & Dabigatran & Rivaroxaban/Apixaban \\
\hline $\begin{array}{l}\text { Standard bleeding risk } \\
\mathrm{CrCl}^{\dagger} \geq 50\end{array}$ & 2 days before & 1 day before \\
$30 \leq \mathrm{CrCl}<50$ & 3 days before & 2 days before \\
$\mathrm{CrCl}<30$ & 4 days before & 2 days before \\
$\mathrm{High} \mathrm{bleeding} \mathrm{risk}$ & & \\
$\mathrm{CrCl} \geq 50$ & 2 days before & 2 days before \\
$30 \leq \mathrm{CrCl}<50$ & 4 days before & 4 days before \\
$\mathrm{CrCl}<30$ & 6 days before & 4 days before \\
\hline
\end{tabular}

*Colonoscopy, uncomplicated laparoscopic procedures, any aspirations not involving the spinal canal; ${ }^{\dagger} \mathrm{mL} / \mathrm{min}$ per $1.73 \mathrm{~m}^{2}$; ${ }^{*}$ Major cardiac surgery, insertion of pacemakers or defibrillators, neurosurgery, major cancer/urologic/vascular surgery, spinal puncture.

renal function. The half-life of dabigatran varies from 14-17 hours with normal renal function to $18-27$ hours in moderate to severe renal impairment. ${ }^{67,68}$ The recently recommended approaches based on these data are summarized in Table $4 .{ }^{69-71}$ The longer overlap period of rivaroxaban and warfarin shown in this table is caused by the shorter half-life of rivaroxaban. ${ }^{72}$ When assessing the INR during transitions between rivaroxaban and warfarin, we need to be cautious because rivaroxaban may increase the prothrombin time. ${ }^{73}$

Perioperative management of the NOACs is based on the urgency of the procedure, bleeding risk, and current renal function. Preoperative discontinuation of the drug is based on pharmacokinetic data and considerations regarding the bleeding risk (Table 5). Interruption of dabigatran for 48 hours should be sufficient to ensure adequate hemostasis in patients with normal renal function because of the half-life of $14-17$ hours. ${ }^{74}$ For procedures with a low risk of bleeding such as cardiac catheterization, diagnostic endoscopy, and minor orthopedic surgery, for which an INR of 1.5 for patients on warfarin would be acceptable, it is reasonable to interrupt dabigatran for 24 hours. In patients with decreased renal function, the period of interruption should be longer. This principle is also applied to rivaroxaban. In the previous trial, ROCKET-AF, rivaroxaban was interrupted approximately 2 days before the procedure. ${ }^{60}$ The short period of interruption does not require bridging therapy with unfractionated heparin or low-molecular-weight heparin. Reinitiation of NOACs after the procedure depends on the postoperative risk of bleeding. For procedures with good hemostasis, the suggestion is to reinitiate NOACs at a minimum of 4-6 hours after the procedure. ${ }^{65}$ The first dose of dabigatran should be a half-dose $(75 \mathrm{mg})$, and the next scheduled dose should be the usual maintenance dose. A similar strategy using a 10-mg dose for the first dose can be applied to rivaroxaban. Patients with bowel paralysis may require bridging with parenteral anticoagulants because they cannot take oral anticoagulants.

\section{Novel strategies to prevent stroke in patients with NVAF}

For strategies to prevent stroke associated with NVAF in addition to antithrombotic therapy, studies on procedures to surgically block the left atrial appendage (LAA), which is the most important position in which thrombus is formed by NVAF, have been conducted. ${ }^{75-77}$ After a device to block LAA is inserted, warfarin is administered for 45 days, and then both aspirin and clopidogrel are administered for 4.5 months. It is not inferior to the group of conventional warfarin use when aspirin monotherapy is administered. ${ }^{78}$ In addition, when long-term follow-up continues for up to 2.3 years, it is non-inferior in occurrence of cardiovascular diseases including stroke compared with the group using warfarin. ${ }^{79}$ Other strategies to prevent stroke associated with NVAF include rhythm control and heart rate control. Previous studies and meta-analyses showed that the beneficial effect between rate control and rhythm control was not different for prevention of stroke. ${ }^{80-85}$ A post-hoc analysis from a recent study showed that dronedarone, a newly developed rhythm control drug, was beneficial in preventing stroke, ${ }^{86}$ but another study using dronedarone in addition to standard therapy for rhythm control showed that dronedarone increased the risk of stroke more than two-fold in comparison with placebo. ${ }^{87} \mathrm{Re}$ cently, a large-sized population-based observational study to compare rhythm control and rate control in patients with atrial fibrillation was conducted in Canada. ${ }^{88}$ Risk for the occurrence of stroke was decreased by $20 \%$ in patients who underwent rhythm control compared with those who underwent rate control. When patients were classified into low-, moderate-, and high-risk groups based on $\mathrm{CHADS}_{2}$ scores, rhythm control was superior to rate control in the moderate- and high-risk groups. To date, a complete conclusion about the effect of rate control and rhythm control on occurrence of stroke associated with NVAF has not been made.

\section{Conclusion}

Knowledge about risk stratification and treatment for stroke associated with NVAF is increasing dramatically. More delicate risk assessment systems make physicians choose adequate preventive strategies to reduce stroke related to NVAF, and NOACs may be additional therapeutic options for these patients in primary and secondary prevention. In this context, there are some clinical practice guidelines for the management of atrial fibrillation patients from the United States and Europe. ${ }^{26,89,90}$ Recently, a clinical practice guideline for stroke prevention was published and revised in Korea, and it includes these issues 
about ischemic stroke associated with NVAF. ${ }^{91}$ Ischemic stroke related to NVAF has been more prevalent, as life expectancy is increasing worldwide, and disease burden is also increasing steeply. Preventive and therapeutic options should be developed and improved in the future.

\section{References}

1. Ferro JM. Cardioembolic stroke: an update. Lancet Neurol 2003; 2:177-188.

2. Arboix A, Alió J. Cardioembolic stroke: clinical features, specific cardiac disorders and prognosis. Curr Cardiol Rev 2010;6: 150.

3. Eriksson S-E, Olsson J-E. Survival and recurrent strokes in patients with different subtypes of stroke: a fourteen-year followup study. Cerebrovasc Dis 2001;12:171-180.

4. Kolominsky-Rabas PL, Weber M, Gefeller O, Neundoerfer B, Heuschmann PU. Epidemiology of ischemic stroke subtypes according to toast criteria incidence, recurrence, and long-term survival in ischemic stroke subtypes: a population-based study. Stroke 2001;32:2735-2740.

5. Ferro JM. Brain embolism. J Neurol 2003;250:139-147.

6. Weir N. An update on cardioembolic stroke. Postgrad Med J 2008;84:133-142.

7. Arboix A, Vericat M, Pujades R, Massons J, Garcia-Eroles L, Oliveres M. Cardioembolic infarction in the sagrat cor-alianza hospital of barcelona stroke registry. Acta Neurol Scand 1997; 96:407-412.

8. Bogousslavsky J, Van Melle G, Regli F. The lausanne stroke registry: analysis of 1,000 consecutive patients with first stroke. Stroke 1988;19:1083-1092.

9. Timsit S, Sacco R, Mohr J, Foulkes M, Tatemichi T, Wolf P, et al. Brain infarction severity differs according to cardiac or arterial embolic source. Neurology 1993;43:728-733.

10. Al-Rajeh S, Larbi E, Bademosi O, Awada A, Ismail H, Al-Freihi $\mathrm{H}$, et al. Stroke in a tertiary hospital in saudi arabia: a study of 372 cases. Eur Neurol 1991;31:251-256.

11. Rothrock JF, Lyden PD, Brody ML, Taft-Alvarez B, Kelly N, Mayer J, et al. An analysis of ischemic stroke in an urban southern California population. The University of California, San Diego, Stroke Data Bank. Arch Intern Med 1993;153:619-624.

12. Norrving B, Löwenhielm P. Epidemiology of stroke in LundOrup, Sweden, 1983-85. Acta Neurol Scand 1988;78:408-413.

13. Jung KH, Lee SH, Kim BJ, Yu KH, Hong KS, Lee BC, et al. Secular trends in ischemic stroke characteristics in a rapidly developed country results from the Korean Stroke Registry Study (secular trends in Korean stroke). Circ Cardiovasc Qual Outcomes 2012;5:327-334.
14. Hong KS, Bang OY, Kang DW, Yu KH, Bae HJ, Lee JS, et al. Stroke statistics in Korea: Part I. Epidemiology and risk factors: a report from the Korean Stroke Society and Clinical Research Center for Stroke. J Stroke 2013;15:2-20.

15. Han SW, Nam HS, Kim SH, Lee JY, Lee KY, Heo JH. Frequency and significance of cardiac sources of embolism in the toast classification. Cerebrovasc Dis 2007;24:463-468.

16. Page RL, Wilkinson WE, Clair WK, McCarthy EA, Pritchett E. Asymptomatic arrhythmias in patients with symptomatic paroxysmal atrial fibrillation and paroxysmal supraventricular tachycardia. Circulation 1994;89:224-227.

17. Strickberger SA, Ip J, Saksena S, Curry K, Bahnson TD, Ziegler PD. Relationship between atrial tachyarrhythmias and symptoms. Heart Rhythm 2005;2:125-131.

18. Hart RG, Pearce LA. Current status of stroke risk stratification in patients with atrial fibrillation. Stroke 2009;40:2607-2610.

19. Wolf PA, Abbott RD, Kannel WB. Atrial fibrillation as an independent risk factor for stroke: The Framingham Study. Stroke 1991;22:983-988.

20. Roger VL, Go AS, Lloyd-Jones DM, Benjamin EJ, Berry JD, Borden WB, et al. Heart disease and stroke statistics--2012 update: a report from the American Heart association. Circulation 2012;125:e2-e220.

21. Wang TJ, Massaro JM, Levy D, Vasan RS, Wolf PA, D’Agostino $\mathrm{RB}$, et al. A risk score for predicting stroke or death in individuals with new-onset atrial fibrillation in the community. JAMA 2003;290:1049-1056.

22. Go AS, Hylek EM, Phillips KA, Chang Y, Henault LE, Selby JV, et al. Prevalence of diagnosed atrial fibrillation in adults. JAMA 2001;285:2370-2375.

23. Murphy NF, Simpson CR, Jhund PS, Stewart S, Kirkpatrick $\mathrm{M}$, Chalmers J, et al. A national survey of the prevalence, incidence, primary care burden and treatment of atrial fibrillation in Scotland. Heart 2007;93:606-612.

24. Heeringa J, van der Kuip DA, Hofman A, Kors JA, van Herpen $\mathrm{G}$, Stricker BHC et al. Prevalence, incidence and lifetime risk of atrial fibrillation: the Rotterdam Study. Eur Heart J 2006;27: 949-953.

25. Jeong HD. Prevalence of and risk factors for atrial fibrillation in Korean adults older than 40 years. J Korean Med Sci 2005;20: 26-30.

26. Fuster V, Ryden LE, Cannom DS, Crijins HJ, Curtis AB, Ellenbogen KA, et al. ACC/AHA/ESC 2006 Guidelines for the Management of Patients with Atrial Fibrillation: a report of the American College of Cardiology/American Heart Association Task Force on Practice Guidelines and the European Society of Cardiology Committee for Practice Guidelines (Writing Committee to Revise the 2001 Guidelines for the Management 
of Patients with Atrial Fibrillation). Circulation 2006;114:e257e354.

27. Frost L, Engholm G, Johnsen S, Møller H, Husted S. Incident stroke after discharge from the hospital with a diagnosis of atrial fibrillation. Am J Med 2000;108:36-40.

28. Frost L, Godtfredsen J, Mortensen L. Age and risk of stroke in atrial fibrillation: evidence for guidelines? Neuroepidemiol 2007; 28:109-115.

29. Gage BF, Waterman AD, Shannon W, Boechler M, Rich MW, Radford MJ. Validation of clinical classification schemes for predicting stroke. JAMA 2001;285:2864-2870.

30. Lip GY, Nieuwlaat R, Pisters R, Lane DA, Crijns HJ. Refining clinical risk stratification for predicting stroke and thromboembolism in atrial fibrillation using a novel risk factor-based approach: the euro heart survey on atrial fibrillation. Chest 2010; 137:263-272.

31. Pisters R, Lane DA, Nieuwlaat R, de Vos CB, Crijns HJ, Lip GY. A novel user-friendly score (HAS-BLED) to assess 1-year risk of major bleeding in patients with atrial fibrillation: the euro heart survey. Chest 2010;138:1093-1100.

32. Camm AJ, Kirchhof P, Lip GY, Schotten U, Savelieva I, Ernst S, et al. Guidelines for the management of atrial fibrillation the task force for the management of atrial fibrillation of the European Society of Cardiology (ESC). Eur Heart J 2010;31:23692429.

33. Lee SH, Ryu WS, Roh JK. Cerebral microbleeds are a risk factor for warfarin-related intracerebral hemorrhage. Neurology 2009;72:171-176.

34. Lovelock CE, Cordonnier C, Naka H, Salman RA-S, Sudlow CL, Sorimachi T, et al. Antithrombotic drug use, cerebral microbleeds, and intracerebral hemorrhage: a systematic review of published and unpublished studies. Stroke 2010;41:12221228.

35. Aguilar M, Hart R, Pearce L. Oral anticoagulants versus antiplatelet therapy for preventing stroke in patients with non-valvular atrial fibrillation and no history of stroke or transient ischemic attacks. Cochrane Database Syst Rev 2007;18:CD006186.

36. Aguilar M, Hart R. Oral anticoagulants for preventing stroke in patients with non-valvular atrial fibrillation and no previous history of stroke or transient ischemic attacks. Cochrane Database Syst Rev 2005;20:CD001927.

37. Hylek EM, Go AS, Chang Y, Jensvold NG, Henault LE, Selby $\mathrm{JV}$, et al. Effect of intensity of oral anticoagulation on stroke severity and mortality in atrial fibrillation. NEng J Med 2003;349: 1019-1026.

38. O’Donnell M, Oczkowski W, Fang J, Kearon C, Silva J, Bradley C, et al. Preadmission antithrombotic treatment and stroke severity in patients with atrial fibrillation and acute ischaemic stroke: an observational study. Lancet Neurol 2006;5:749-754.

39. Ay H, Arsava EM, Gungor L, Greer D, Singhal AB, Furie KL, et al. Admission international normalized ratio and acute infarct volume in ischemic stroke. Ann Neurol 2008;64:499-506.

40. Agarwal S, Hachamovitch R, Menon V. Current trial-associated outcomes with warfarin in prevention of stroke in patients with nonvalvular atrial fibrillation: a meta-analysis. Arch Intern Med 2012;172:623-631.

41. Paciaroni M, Agnelli G, Ageno W, Caso V, Corea F, Lanari A, et al. Risk factors for cerebral ischemic events in patients with atrial fibrillation on warfarin for stroke prevention. Atherosclerosis 2010;212:564-566.

42. Albertsen IE, Rasmussen LH, Overvad TF, Graungaard T, Larsen TB, Lip GY. Risk of stroke or systemic embolism in atrial fibrillation patients treated with warfarin: a systematic review and meta-analysis. Stroke 2013;44:1329-1336.

43. Kim D, Chung JW, Kim CK, Ryu WS, Park ES, Lee SH, et al. Impact of CHADS(2) score on neurological severity and longterm outcome in atrial fibrillation-related ischemic stroke. $J$ Clin Neurol 2012;8:251-258.

44. Hong H, Kim Y, Cha MJ, Kim J, Lee D, Lee H, et al. Early neurological outcomes according to CHADS2 score in stroke patients with non-valvular atrial fibrillation. Eur J Neurol 2012;19: 284-290.

45. Lin PJ. Reviewing the reality: why we need to change. Eur Heart J2005;7:e15-e20.

46. Oake N, Fergusson DA, Forster AJ, van Walraven C. Frequency of adverse events in patients with poor anticoagulation: a meta-analysis. CMAJ 2007;176:1589-1594.

47. Ahrens I, Lip GY, Peter K. New oral anticoagulant drugs in cardiovascular disease. Arch Intern Med emost 2010;104:49-60.

48. Connolly SJ, Ezekowitz MD, Yusuf S, Eikelboom J, Oldgren J, Parekh A, et al. Dabigatran versus warfarin in patients with atrial fibrillation. N Eng J Med 2009;361:1139-1151.

49. Gran ger CB, Alexander JH, McMurray JJ, Lopes RD, Hylek EM, Hanna M, et al. Apixaban versus warfarin in patients with atrial fibrillation. N Eng J Med 2011;365:981-992.

50. Patel MR, Mahaffey KW, Garg J, Pan G, Singer DE, Hacke W, et al. Rivaroxaban versus warfarin in nonvalvular atrial fibrillation. NEng J Med 2011;365:883-891.

51. Pengo V, Crippa L, Falanga A, Finazzi G, Marongiu F, Palareti $\mathrm{G}$, et al. Questions and answers on the use of dabigatran and perpectives on the use of other new oral anticoagulants in patients with atrial fibrillation. Thromb Haemost 2012;108:65-73.

52. Wallentin L, Yusuf S, Ezekowitz MD, Alings M, Flather M, Franzosi MG, et al. Efficacy and safety of dabigatran compared with warfarin at different levels of international normalised ratio control for stroke prevention in atrial fibrillation: an analysis of 
the RE-LY trial. Lancet 2010;376:975-983.

53. Cotton BA, McCarthy JJ, Holcomb JB. Acutely injured patients on dabigatran. Thromb Haemost 2011;365:2039-2040.

54. Hori M, Connolly SJ, Zhu J, Liu LS, Lau CP, Pais P, et al. Dabigatran versus warfarin: effects on ischemic and hemorrhagic strokes and bleeding in Asians and non-Asians with atrial fibrillation. Stroke 2013;44:1891-1896.

55. Karthikeyan G, Eikelboom JW, Hirsh J. Dabigatran: ready for prime time. Pol Arch Med Wewn 2010;120:137-142.

56. Hohnloser SH, Oldgren J, Yang S, Wallentin L, Ezekowitz M, Reilly $\mathrm{P}$, et al. Myocardial ischemic events in patients with atrial fibrillation treated with dabigatran or warfarin in the RE-LY (Randomized Evaluation of Long-Term Anticoagulation Therapy) trial. Circulation 2012;125:669-676.

57. Uchino K, Hernandez AV. Dabigatran association with higher risk of acute coronary events: meta-analysis of noninferiority randomized controlled trials. Arch Intern Med 2012;172:397402.

58. Hankey GJ, Eikelboom JW. Dabigatran etexilate. Circulation 2011;123:1436-1450.

59. van Ryn J, Stangier J, Haertter S, Liesenfeld KH, Wienen W, Feuring M, et al. Dabigatran etexilate--a novel, reversible, oral direct thrombin inhibitor: interpretation of coagulation assays and reversal of anticoagulant activity. Thromb Haemost 2010; 103:1116-1127.

60. Kubitza D, Becka M, Zuehlsdorf M, Mueck W. Effect of food, an antacid, and the $\mathrm{H} 2$ antagonist ranitidine on the absorption of BAY 59-7939 (rivaroxaban), an oral, direct factor Xa inhibitor, in healthy subjects. J Clin Pharmacol 2006;46:549-558.

61. Hori M, Matsumoto M, Tanahashi N, Momomura S, Goto S, Izumi T, et al. Safety and efficacy of adjusted dose of rivaroxaban in Japanese patients with non-valvular atrial fibrillation: subanalysis of J-ROCKET AF for patients with moderate renal impairment. Circ J 2013;77:632-638.

62. Perzborn E, Roehrig S, Straub A, Kubitza D, Mueck W, Laux V. Rivaroxaban: a new oral factor xa inhibitor. Arterioscler Thrombo Vasc Biol 2010;30:376-381.

63. Wong PC, Pinto DJ, Zhang D. Preclinical discovery of apixaban, a direct and orally bioavailable factor Xa inhibitor. J Thromb Thrombolysis 2011;31:478-492.

64. Raghavan N, Frost CE, Yu Z, He K, Zhang H, Humphreys WG, et al. Apixaban metabolism and pharmacokinetics after oral administration to humans. Drug Metab Dispos 2009;37:74-81.

65. Ezekowitz MD, Connolly S, Parekh A, Reilly PA, Varrone J, Wang S, et al. Rationale and design of RE-LY: randomized evaluation of long-term anticoagulant therapy, warfarin, compared with dabigatran. Am Heart J2009; 157:805-810.

66. Schulman S, Kearon C, Kakkar AK, Schellong S, Eriksson H,
Baanstra D, et al. Extended use of dabigatran, warfarin, or placebo in venous thromboembolism. N Eng J Med 2013;368: 709-718.

67. Stangier J, Rathgen K, Stähle H, Mazur D. Influence of renal impairment on the pharmacokinetics and pharmacodynamics of oral dabigatran etexilate. Clin Pharmacokinet 2010;49:259268.

68. Stangier J, Rathgen K, Stähle H, Gansser D, Roth W. The pharmacokinetics, pharmacodynamics and tolerability of dabigatran etexilate, a new oral direct thrombin inhibitor, in healthy male subjects. Br J Clin Pharmacol 2007;64:292-303.

69. Huisman MV, Lip GY, Diener HC, Brueckmann M, van Ryn J, Clemens A. Dabigatran etexilate for stroke prevention in patients with atrial fibrillation: resolving uncertainties in routine practice. Thromb Haemost 2012;107:838-847.

70. Turpie AG, Kreutz R, Llau J, Norrving B, Haas S. Management consensus guidance for the use of rivaroxaban--an oral, direct factor Xa inhibitor. Thromb Haemost 2012;108:876-886.

71. Schulman S, Crowther MA. How I treat with anticoagulants in 2012: new and old anticoagulants, and when and how to switch. Blood 2012;119:3016-3023.

72. Fleming TR, Emerson SS. Evaluating rivaroxaban for nonvalvular atrial fibrillatio--regulatory considerations. $N$ Eng J Med 2011;365:1557-1559.

73. Samama MM, Martinoli JL, LeFlem L, Guinet C, Plu-Bureau G, Depasse F, et al. Assessment of laboratory assays to measure rivaroxaban-an oral, direct factor Xa inhibitor. Thromb Haemost 2010;103:815-825.

74. Mahtani KR, Heneghan CJ, Nunan D, Bankhead C, Keeling D, Ward AM, et al. Optimal loading dose of warfarin for the initiation of oral anticoagulation. Cochrane Database Syst Rev 2012; 12:CD008685.

75. Sick PB, Schuler G, Hauptmann KE, Grube E, Yakubov S, Turi $Z G$, et al. Initial worldwide experience with the WATCHMAN left atrial appendage system for stroke prevention in atrial fibrillation. J Am Coll Cardiol 2007;49:1490-1495.

76. Stone D, Byrne T, Pershad A. Early results with the LARIAT device for left atrial appendage exclusion in patients with atrial fibrillation at high risk for stroke and anticoagulation. Catheter Cardiovasc Interv 2013; doi: 10.1002/ccd.25065.

77. Bartus K, Han FT, Bednarek J, Myc J, Kapelak B, Sadowski J, et al. Percutaneous left atrial appendage suture ligation using the LARIAT device in patients with atrial fibrillation: initial clinical experience. J Am Coll Cardiol 2013;62:108-118.

78. Holmes DR, Reddy VY, Turi ZG, Doshi SK, Sievert H, Buchbinder $\mathrm{M}$, et al. Percutaneous closure of the left atrial appendage versus warfarin therapy for prevention of stroke in patients with atrial fibrillation: a randomised non-inferiority trial. Lan- 
cet 2009;374:534-542.

79. Reddy VY, Doshi SK, Sievert H, Buchbinder M, Neuzil P, Huber K, et al. Percutaneous left atrial appendage closure for stroke prophylaxis in patients with atrial fibrillation: 2.3-Year Followup of the PROTECT AF (Watchman Left Atrial Appendage System for Embolic Protection in Patients with Atrial Fibrillation) Trial. Circulation 2013;127:720-729.

80. Van Gelder IC, Hagens VE, Bosker HA, Kingma JH, Kamp O, Kingma T, et al. A comparison of rate control and rhythm control in patients with recurrent persistent atrial fibrillation. $N$ Eng J Med 2002;347:1834-1840.

81. Opolski G, Torbicki A, Kosior DA, Szulc M, WozĚ B, KoĹ P, et al. Rate control vs rhythm control in patients with nonvalvular persistent atrial fibrillation: the results of the Polish How to Treat Chronic Atrial Fibrillation (HOT CAFE) Study. Chest 2004;126:476-486.

82. Sherman DG, Kim SG, Boop BS, Corley SD, DiMarco JP, Hart $\mathrm{RG}$, et al. Occurrence and characteristics of stroke events in the Atrial Fibrillation Follow-up Investigation of Sinus Rhythm Management (AFFIRM) study. Arch Intern Med 2005;165: 1185-1191.

83. de Denus S, Sanoski CA, Carlsson J, Opolski G, Spinler SA. Rate vs rhythm control in patients with atrial fibrillation: a meta-analysis. Arch Intern Med 2005; 165:258-262.

84. Kumana CR, Cheung BM, Cheung GT, Ovedal T, Pederson B, Lauder IJ. Rhythm vs. rate control of atrial fibrillation meta-analysed by number needed to treat. Br J Clin Pharmacol 2005; 60:347-354.
85. Caldeira D, David C, Sampaio C. Rate vs rhythm control in patients with atrial fibrillation and heart failure: a systematic review and meta-analysis of randomised controlled trials. Eur J Intern Med 2011;22:448-455.

86. Connolly SJ, Crijns HJ, Torp-Pedersen C, van Eickels M, Gaudin C, Page RL, et al. Analysis of stroke in ATHENA: a placebocontrolled, double-blind, parallel-arm trial to assess the efficacy of dronedarone $400 \mathrm{mg}$ BID for the prevention of cardiovascular hospitalization or death from any cause in patients with atrial fibrillation/atrial flutter. Circulation 2009;120:1174-1180.

87. Connolly SJ, Camm AJ, Halperin JL, Joyner C, Alings M, Amerena J, et al. Dronedarone in high-risk permanent atrial fibrillation. N Eng J Med 2011;365:2268-2276.

88. Tsadok MA, Jackevicius CA, Essebag V, Eisenberg MJ, Rahme $\mathrm{E}$, Humphries $\mathrm{KH}$, et al. Rhythm versus rate control therapy and subsequent stroke or transient ischemic attack in patients with atrial fibrillation. Circulation 2012;126:2680-2687.

89. Guyatt GH, Akl EA, Crowther M, Guttherman DD, Schuunemann HJ. Executive summary: Antithrombotic Therapy and Prevention of Thrombosis, 9th ed: American College of Chest Physicians Evidence-Based Clinical Practice Guidelines. Chest 2012;141:7S-47S.

90. Lip GY, Rundolf M. The new NICE guideline on atrial fibrillation management. Heart 2007;93:23.

91. Clinical Research Center for Stroke. Clinical Practice Guidelines for Stroke. 2013. ISBN: 978-89-94181-19-6. http://www. stroke-crc.or.kr 